\title{
THE ARCHITECTURE OF PAGODAS VIEWED FROM THE ANGLE OF SITE LAY-OUT, PROPORTION, AND SYMBOLIZATION
}

\author{
${ }^{1}$ Raymond William. ${ }^{2}$ Dr. Ir. Yuswadi Saliya, M. Arch \\ ${ }^{1}$ Student in the Bachelor's (S-1) Study Program in Architecture \\ at Parahyangan Catholic University \\ ${ }^{2}$ Senior lecturer in the Bachelor's (S-1) Study Program in Architecture \\ at Parahyangan Catholic University
}

\begin{abstract}
On Bali the islanders enjoy a close relationship with their Creator. The majority of Balinese worship in temples or shrines called Pura. These form a complex of sacred buildings that have a certain significance and function. One prominent type is the so-called Meru or Pagoda. Not all Pura temples have such a pagoda, but those that have more than one are found quite frequently. The placement of a pagoda in a temple is usually made at the main section due to its holiness or purity. Their shape differs from other constructions because their layered roof is multi-tiered, always uneven in number, starting from 3 up to 11. Therefore, these pagodas attain a different height so that their proportions are interesting to observe in order to determine whether there is a pole (patokan) or not. The pagodas carry divine symbols, ones referring to other temples or shrines, or ancestral symbols. This study employs the descriptive-analytical method by conducting a qualitativequantitative evaluation. The qualitative evaluation investigates the lay-out of the placement and examines symbolization, whereas the quantitative evaluation studies the proportions of the pagodas. The data collection technique contains three parts, namely studying the relevant background literature, making observations, and holding structured interviews. The data analysis subjects the outcome of the observations and interviews to analysis, to be joined with theoretical study. The conclusion may be drawn that the ordering principle behind the placement of pagodas is situated in the main area, considered the most sacred part of a Pura temple. These proportions prove to have several features in common by comparison, so that it can be turned into a pole (patokan). No uniformity was detected in the symbolization of the pagoda in terms of carvings or the number of joinings.
\end{abstract}

Keywords: pagoda, site lay-out, proportion, symbolization, temples on Bali

\section{ARSITEKTUR BANGUNAN MERU DITINJAU DARI TATA LETAK, PROPORSI, DAN SIMBOLISASI}

\author{
${ }^{1}$ Raymond William. ${ }^{2}$ Dr. Ir. Yuswadi Saliya, M. Arch \\ ${ }^{1}$ Mahasiswa S1 Program Studi Arsitektur Universitas Katolik Parahyangan. \\ ${ }^{2}$ Dosen Pembimbing S1 Program Studi Arsitektur Universitas Katolik Parahyangan.
}

${ }^{1}$ Corresponding author: rmondw@icloud.com 


\begin{abstract}
Abstrak- Bali merupakan salah satu provinsi di Indonesia yang sangat kental dengan kedekatan manusia dengan Pencipta-nya. Mayoritas masyarakat Bali mengucapkan syukurnya kepada Pencipta-nya dalam tempat Ibadah yang disebut Pura. Pura merupakan suatu kompleks bangunan-bangunan suci dengan makna dan fungsinya masing-masing. Bangunan yang menarik perhatian adalah Meru. Tidak semua Pura memiliki Meru, tetapi tidak jarang pula dalam 1 Pura terdapat lebih dari 1 Meru. Peletakan bangunan Meru pada suatu Pura biasanya di bagian paling utama karena kesucian bangunan Meru. Meru memiliki bentuk yang berbeda dari bangunan lainnya karena atapnya yang bertingkattingkat. Tingkatan atap Meru selalu ganjil dimulai dari 3 sampai 11. Oleh karena itu Meru memiliki tinggi yang berbeda-beda sehingga proporsinya pun menarik untuk ditinjau apakah ada patokan atau tidak. Meru memiliki makna bermacam-macam seperti simbol Tuhan, simbol terhadap pura lain, atau simbol leluhur. Penelitian ini menggunakan metode analisis deskriptif dengan melakukan evaluasi secara kualitatif dan kuantitatif. Evaluasi kualitatif digunakan untuk mengkaji tata letak dan simbolisasi, sedangkan evaluasi kuantitatif digunakan untuk mengkaji proporsi pada bangunan Meru. Teknik pengumpulan data dibagi menjadi 3 yaitu studi literature, observasi, dan wawancara terstruktur. Analisa data dilakukan dengan menganalisis data hasil observasi dan wawancara dengan narasumber, lalu digabungkan dengan kajian teori. Berdasarkan hasil analisis penelitian didapatkan bahwa tata letak bangunan Meru berada di Utama Mandala yang merupakan area paling suci pada suatu Pura. Proporsi bangunan Meru terbukti memilik beberapa kesamaan dalam perbandingan sehingga dapat dijadikan patokan / standar. Simbolisasi bangunan Meru tidak ditemukan keseragaman dilihat dari ukiran maupun jumlah tumpang.
\end{abstract}

Kata Kunci: meru, tata letak, proporsi, simbolisasi, pura di bali

\title{
1. PENDAHULUAN
}

Bali merupakan salah satu provinsi di Indonesia yang dipandang baik oleh dunia. Bali kaya akan budaya yang ada pada masyarakatnya turun temurun dari dahulu. Masyarakat Bali memiliki keyakinan pada 3 elemen di bumi ini, yaitu Tuhan, manusia, dan alam. Kedekatan manusia dengan alam dan Pencipta-nya sangat kental terasa. Masyarakat Bali juga selalu bersyukur kepada Tuhan melalui sembahyang dan mendekatkan diri pada Tuhan. Tempat pemujaan masyarakat Bali yang mayoritas beragama Hindu ini dilakukan di tempeh ibadah yang disebut Pura.

Pura merupakan tempat ibadah agama Hindu yang sangat kompleks. Terdiri dari beberapa bangunan dan pelinggih-pelinggih dengan makna dan fungsinya masing-masing. Bangunan yang menarik perhatian adalah Meru. Tidak semua Pura memiliki Meru. Namun tidak jarang pula dalam 1 Pura terdapat lebih dari 1 bangunan Meru.

Bangunan Meru merupakan salah satu pelinggih utama dalam suatu Pura. Meru merupakan bangunan yang sangat suci sehingga peletakannya seharusnya dibagian paling utama dalam suatu Pura. Bangunan Meru memiliki bentuk yang berbeda dari bangunan / pelinggih lainnya karena Meru memiliki atap yang bertingkat-tingkat. Tingkatan atap Meru selalu berjumlah ganjil dimulai dari 3 sampai 11 tingkat. Bangunan Meru memiliki makna dan simbolnya juga, ada Meru yang merupakan simbol dari Tuhan, atau simbol terhadap Pura lain, atau simbol dari leluhur.

Dari penjelasan singkat bangunan Meru diatas, didapatkan rumusan masalah yang muncul pada penelitian ini antara lain: (1) Bagaimana pola tata letak Bangunan Meru pada Pura? (2) Bagaimana proporsi antar Bangunan Meru di Pura yang satu dibandingkan dengan di Pura lainnya? (3) Bagaimana pemaknaan simbolisasi yang terkandung dalam arsitektur bangunan meru?

Penelitian ini memiliki tujuan agar pembaca dapat mengetahui tata letak dan orientasi bangunan Meru pada Pura, mengetahui proporsi bangunan Meru, dan mengetahui perbedaan makna pada simbolisasi bangunan Meru. Manfaat dari penelitian ini diharapkan dapat melestarikan arsitektur bangunan Meru tanpa kehilangan makna, dapat menambahkan ilmu tentang bangunan Meru agar jika ada kerusakan, dapat dipugar dengan benar. 
Objek penelitian berada di Pura Uluwatu, Pura Ulun Danu Batur, Pura Batukaru, Pura Penataran Agung Besakih, Pura Goa Lawah, Pura Gunung Lebang, Pura Kehen, Pura Yeh Gangga, Pura Desa Sukawati, Pura Desa Penglipuran, Pura Keluarga Puri Saba, dan Pura Taman Ayun. Observasi lapangan dilaksanakan dua kali, yaitu pada akhir Januari sampai awal Februari 2016, dan dilanjutkan pada awal Maret 2016.

Metode penelitian yang digunakan adalah metode analisis deskriptif, dengan melakukan evaluasi secara kualitatif dan kuantitatif. Evaluasi kualitatif digunakan untuk mengkaji tata letak dan simbolisasi, sedangkan evaluasi kuantitatif digunakan untuk mengkaji proporsi pada bangunan Meru. Teknik pengumpulan data dibagi menjadi 3, yaitu studi literatur, observasi, dan wawancara terstruktur. Teknik analisa data dilakukan dengan menganalisis data hasil observasi langsung dan hasil wawancara terstruktur dengan narasumber, Analisis ini diperkuat dengan hasil dokumentasi, lalu data tersebut digabungkan dengan kajian teori yang didapat dari studi literatur. Hasil analisis perbandingan keduanya ini menghasilkan suatu kesimpulan yang merupakan jawaban rumusan masalah penelitian.

\section{TEORI}

\subsection{PRINSIP-PRINSIP BANGUNAN MERU PADAARSITEKTUR BALI}

Masyarakat tradisionil maupun modern memandang bumi sebagai suatu kehidupan. Pandangan tersebut membawa sikap tunduk pada alam. Masyarakat tradisionil menempatkan dan memperlakukan alam dengan anggapan mempunyai persamaan unsur dengan dirinya. Demikian pula arsitekturnya dipandang sebagai suatu kehidupan, antara manusia dan alamnya.

Tata nilai fisiknya manusia yang dibedakan antara kepala, badan, dan kaki, juga menyelaraskan penilaiannya terhadap alam dengan membedakan nilai pegunungan, dataran pemukiman dan pantai laut.

Pada Arsitektur Tradisionil dibagi pula dengan pembagian atap sebagai kepala, tiang dan tembok dinding sebagai badan, dan lantai pondasi sebagai kaki. Sedangkan pada bumi, pegunungan sebagai ketenangan tempat suci, dataran pemukiman sebagai tempat aktivitas kehidupan manusia, laut sebagai tempat pembuangan akhir dari segala sisa di bumi. Sedangkan pula pada manusia, kepala sebagai pusat panca indra, badan sebagai pusat aktivitas kerja, dan kaki sebagai penerus berat badan ke bumi.

Arsitektur Tradisionil Bali pada prinsipnya menjaga keseimbangan kelima unsur pembentuk manusia dengan alam, yaitu air, panas, udara, angin, dan zat padat pembentuk fisik manusia maupun fisik alam.

Arsitektur yang mewadahi aktivitas manusia dalam kehidupannya di bumi dibedakan menurut fungsi yang dijalinnya. Arsitektur tradisionil menjadikan keseimbangan antara manusia tradisionil dengan alam setempat. Permasalahan keseimbangan akan timbul apabila pemakai Arsitektur Tradisionil adalah turis sebagai manusia non tradisionil. Dalam hal ini, turis-lah yang harus menyesuaikan diri dengan keadaan setempat, dengan demikian tercapailah keseimbangan antara turis, masyarakat setempat, alam, dan arsitekturnya.

Masyarakat Bali masih sangat kental akan budaya. Salah satu budaya yang menjadi obyek wisata adalah ritual sembahyang yang dilakukan kebanyakan masyarakat bali. Masyarakat Bali terkenal dengan masyarakat yang rajin sembahyang. Hal ini sudah dikenal dimata dunia. 
Untuk memuja Tuhan, dibangun tempat-tempat pemujaan. Tempat ibadah adalah bangunan-bangunan suci yang dibangun di tempat suci atau tempat-tempat yang disucikan. Karena di Bali mayoritas umat Hindu, oleh karena itu tempat pemujaannya berupa Pura.

Dilihat dari sumber www.komangputra.com/struktur-makna-pura-di-baliberdasarkan-astakosala-kosali.html, Konsep bangunan Pura di Bali mengacu pada pemahaman umat Hindu Bali terhadap Alam dan ajaran agama Hindu. Konsep pembangunan Pura mengacu pada Asta KosalaKosali yang di dalamnya terdapat falsafah perwujudan arsitektur Pura yaitu Tri Hita Karana, Panca Maha Bhuta, Nawa Sanga.

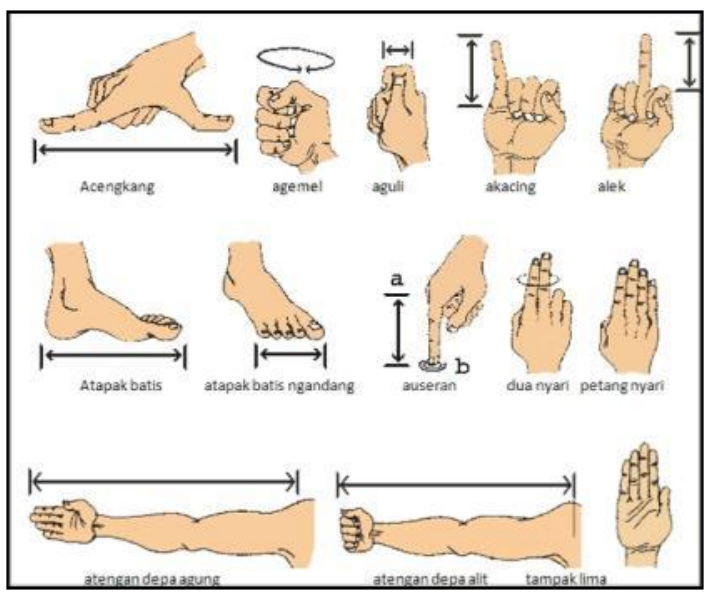

Figur 1. Asta Kosala-Kosali

(Sumber: cakepane.blogspot.co.id, Maret 2016)

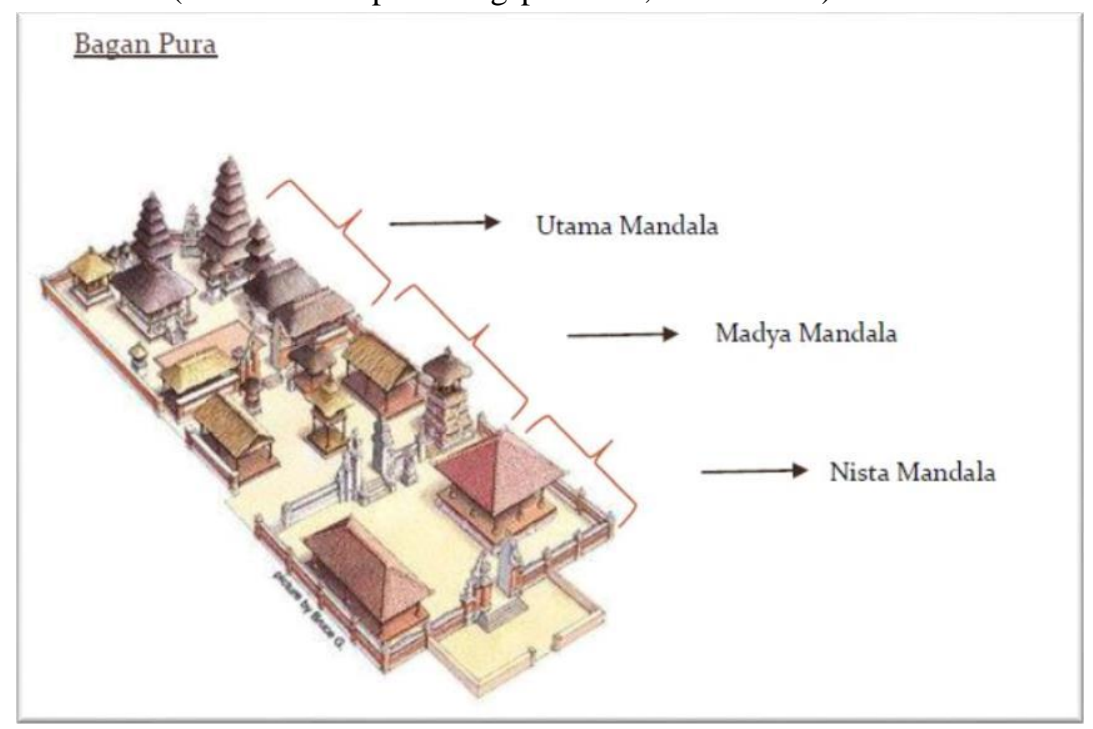

Figur 2. Tri Mandala

(Sumber: hindualukta.blogspot.com, Maret 2016)

Pada umumnya Pura di Bali menggunakan struktur denah Pura Tri Mandala, yaitu Pura dibagi menjadi 3 bagian, antara lain: (1) Jabapura / Jaba Sisi (halaman luar), (2) Jaba tengah (halaman tengah), dan (3) Jeroan (halaman dalam) 


\subsubsection{ZONA DEPAN / JABA SISI (NISTA MANDALA)}

Merupakan tempat peralihan dari luar Pura ke dalam Pura. Pada bagian ini biasanya umat masih sedikit terkontaminasi oleh area luar Pura, maka mereka menyucikan dan menenangkan diri. Bagian ini merupakan bagian nista / kotor dan tidak sakral. Bangunan yang terdapat pada mandala ini diantaranya: (a) Bale kulkul, sebagai tempat memanggil umat sebelum upacara, (b) Bale Wantilan, balai tempat pementasan kesenian, (c) Bale Pawaregan, digunakan sebagai dapur tempat sesajen dibuat, (d) Lumbung, digunakan untuk menyimpan beras.

\subsubsection{ZONA TENGAH / JABA TENGAH (MADYA MANDALA)}

Merupakan tempat persiapan dan pengiring upacara. Bagian ini merupakan bagian dalam pura yang sakral. Pada bagian ini umat sudah mulai fokus menghadap Sang Hyang Widi Wasa. Bangunan yang terdapat pada mandala ini diantaranya: (a) Bale Agung (Bale Panjang), (b) Bale Gong, (c) Bale Panyimpenan, tempat menyimpan barang berharga Pura.

\subsubsection{ZONA UTAMA/JEROAN (UTAMA MANDALA)}

Merupakan tempat paling sakral dan suci. Pada bagian ini merupakan tempat pelaksanaan pemujaan persembahyangan. Umat harus benar-benar fokus untuk menghadap Sang Hyang Widhi dengan meninggalkan nafsu keduniawiannya. Bangunan yang terdapat pada mandala ini diantaranya: (a) Padmasana, untuk menstanakan Sang Hyang Widhi (b) Pelinggih-pelinggih (c) Bale Piasan (d) Panglurah, tempat pengawal Sang Hyang Widhi.

\subsection{TATA LETAK, PROPORSI, DAN SIMBOLISASI BANGUNAN MERU}

\subsubsection{TATA LETAK}

Dilihat dari sumber Studi Komprehensif - Meru yang ditulis oleh I Made Rai Wiryatmika tahun 1988, Meru di Bali biasanya terdapat di dalam pura-pura yang memiliki hierarki sebagai Sad Kahyangan, Kahyangan Jagad, Kahyangan Tiga, atau Pamerajan Agung. Meru pada suatu pura secara tata letak berada pada tempat pemujaan di halaman utama (jeroan) dari suatu pura.

Dari segi orientasi, meru umumnya menghadap ke barat sebagai tempat pemujaan utama berderet pada sisi timur dari utara ke selatan (kaja-kelod) dengan bangunan-bangunan padma, gedong, dan pemujaan suci lainnya sehingga arah pemujaan menghadap ke timur ke arah matahari terbit.

Perletakan meru tersebut juga dipengaruhi oleh keadaan lokal dan filosofi tertentu, misalnya bergantung pada arah Gunung Agung.

\subsubsection{PROPORSI}

Berdasarkan sumber bali-airport.com/detail/wisata/meru, Bangunan Meru biasanya sangat menonjol karena atapnya bertingkat-tingkat. Jumlah tumpang pada atapnya selalu ganjil, dimulai dari 3, 5, 7, 9, sampai 11. Meru dibangun berdasarkan pada keakuratan proporsi, logika teknik konstruksi dan keindahan ragam hias. Dasar-dasar ini berpegang teguh kepada kearifan lokal arsitektur tradisional Bali seperti Asta Kosala Kosali, Hasta Bumi, Lontar Andha Buana, Lontar Jananthaka, dll. 
Ciri umum bangunan Meru adalah bentuk bangunan dasarnya segi empat. Dan jika dilihat dari tampak, dapat dibedakan menjadi 3 bagian: kaki (bebaturan), badan (ruang pemujaan atau tempat meletakkan pratima), dan kepala (atap). Di bagian muka biasanya terdapat tangga.

Badan Meru yang berupa ruang pemujaan dibentuk empat tiang sudut dirangkai dengan sambungan sunduk di bawah dan sambungan lambang-sineb di atasnya. Dinding ruang badan Meru tersebut dibuat dari papan pada sisi belakang dan sisi-sisi sampingnya, dan pada sisi depannya terdapat pintu. Ada pula yang keempat sisinya berupa pintu, tetapi ada pula yang terbuka tidak menggunakan pintu sama sekali. Ruang Meru tersebut berfungsi sebagai tempat sesaji.

\subsubsection{SIMBOLISASI}

Berdasarkan sumber Studi Komprehensif - Meru yang ditulis oleh I Made Rai Wiryatmika tahun 1988, Meru tergolong agung atau utama biasanya dilengkapi dengan tiangtiang berjajar di keempat sisinya beserta komponen atapnya. Hiasan ukiran pada pintu dan tiang-tiang jajar biasanya bermotif singa bersayap, karang tapel, atau kera penyangga tiang.

Atapnya selalu bertingkat ganjil dan menggunakan struktur kayu. Setiap sambungan yang ada berupa sambungan tradisional pertemuan kayu dengan kayu, tanpa menggunakan paku. Atapnya menggunakan bahan penutup berupa ijuk yang saling diikat. Konstruksinya tumpang dimana rangka tiang-tiang pada masing-masing segmen tingkatan menumpu pada titimahmah (balok melintang-tumpuan tiang diatasnya). Pengikat tumpang-tumpang selain titimahmah, dapat pula berupa tiang beti yang menerus dari tengah ruang dan mengikat tumpang-tumpang atap.

Penggunaan atap Meru selain akibat pengaruh religi, diperkirakan juga karena alasan kemudahan / kegunaan. Bahan ijuk tentunya lebih mudah dibuat daripada harus membuat bata dan batu. Atap meru ini juga dianggap lebih ampuh menahan gempa daripada menggunakan batu / bata. Selain itu diperkirakan juga karena lebih mudah untuk dipindahkan (non-permanen secara struktur) apabila terjadi sesuatu misalnya perang atau bencana.

Atap Meru dibuat dari ijuk sehingga tidak bisa diukir. Gambaran semakin-jauhsemakinmengecil ditunjukkan melalui bentuk bagian atap meru berupa piramid-piramid terpancung yang berbeda ukurannya, semakin ke atas semakin kecil tetapi tetap mempunyai proporsi yang sama. Selain karena alasan struktur (untuk mengurangi beban agar tidak menggoyahkan struktur di bawahnya).

Konsep penggunaan angka ganjil pada jumlah komponen tingkatan atap di dalam bangunan saktral tergantung dari agamanya, Dalam agama Hindu dikenal konsep kosmologi pusat dan yang arah mengelilinginya. Hal itu dapat dilihat misalnya Siwa (1) yang dikelilingi Astadipalaka (8), jadi totalnya 9 (ganjil); Nawasanga (1 tinti petak dikelilingi 8 petak) atau 33 tingkatan dalam catra Stupa Budhisme, dsb.

Konsep ini menunjukakan adanya kecenderungan untuk 'mengganjilkan yang genap' atau ditutup dengan sesuatu sehingga berjumlah ganjil. Ganjil tersebut pada akhirnya mengacu kepada ketunggalan atau tidak diduakan.

Pada umumnya bangunan Meru yang ditujukan untuk Sang Hyang Widhi dibuat lebih besar dan kadang-kadang badan meru dibuat dari bahan batu bata. Pada dasar Meru ada juga yang menggunakan ukiran dengan relief dan dibelit oleh satu atau dua ekor naga. 


\section{PEMBAHASAN ANALISA MERU}

\begin{tabular}{|c|c|c|c|c|}
\hline & Sad Kahyangan & Dhang Kahyangan & Desa & Keluarga \\
\hline Laut & Pura Uluwatu & Pura Goa Lawah & - & $\begin{array}{c}\text { Pura Keluarga Puri } \\
\text { Saba }\end{array}$ \\
\hline Datar & Pura Ulun Danu Batur & Pura Gunung Lebah & $\begin{array}{l}\text { Pura Desa } \\
\text { Sukawati }\end{array}$ & Pura Taman Ayun \\
\hline \multirow{2}{*}{ Gunung } & Pura Batukaru & Pura Kehen & \multirow{2}{*}{$\begin{array}{c}\text { Pura Desa } \\
\text { Penglipuran }\end{array}$} & \multirow{2}{*}{ - } \\
\hline & $\begin{array}{c}\text { Pura Penataran Agung } \\
\text { Besakih }\end{array}$ & Pura Yeh Gangga & & \\
\hline
\end{tabular}

Figur 3. Objek Penelitian

\begin{tabular}{|c|l|c|c|c|c|c|}
\hline \multirow{2}{*}{ No } & \multirow{2}{*}{ Nama Pura } & \multicolumn{3}{|c|}{ Jumlah Meru, tumpang: } \\
\cline { 2 - 6 } & & $\mathbf{3}$ & $\mathbf{5}$ & $\mathbf{7}$ & $\mathbf{9}$ & $\mathbf{1 1}$ \\
\hline 1 & Pura Uluwatu & 1 & & & \\
\hline 2 & Pura Ulun Danu Batur & 1 & 1 & 1 & 3 & 1 \\
\hline 3 & Pura Batukaru & 2 & 3 & 1 & & \\
\hline 4 & Pura Penataran Agung Besakih & 2 & 2 & 2 & 1 & 4 \\
\hline 5 & Pura Goa Lawah & 1 & & 1 & & 1 \\
\hline 6 & Pura Gunung Lebah & 1 & 1 & 1 & \\
\hline 7 & Pura Kehen & & & & \\
\hline 8 & Pura Yeh Gangga & & & 1 & \\
\hline 9 & Pura Desa Sukawati & & 1 & 2 & \\
\hline 10 & Pura Desa Penglipuran & 2 & 1 & & 1 & \\
\hline 11 & Pura Keluarga Puri Saba & & 1 & 1 & 2 \\
\hline 12 & Pura Taman Ayun & & & 4 \\
\hline
\end{tabular}

Figur 4. Jumlah Meru pada Pura Objek Penelitian

Seluruh 49 Meru yang telah diobservasi, dianalisis berdasarkan poin-poin tata letak, proporsi, dan simbolisasi: 


\subsection{TATA LETAK}

Analisis tata letak dilihat dari lokasi dan orientasi bangunan Meru berada pada daerah mana suatu Pura. Analisis dapat dilakukan dengan melihat denah. Lalu ditinjau pula orientasi Meru tersebut apakah menghadap ke suatu objek bila scope tinjauan diperluas menjadi Pulau Bali.



Meru Tumpang 3

$5 \quad$ Meru Tumpang 5

Nista Mandala

Meru Tumpang 7

Madya Mandala

$9 \quad$ Meru Tumpang 9

$11 \square \quad$ Meru Tumpang 11

\section{Utama Mandala}

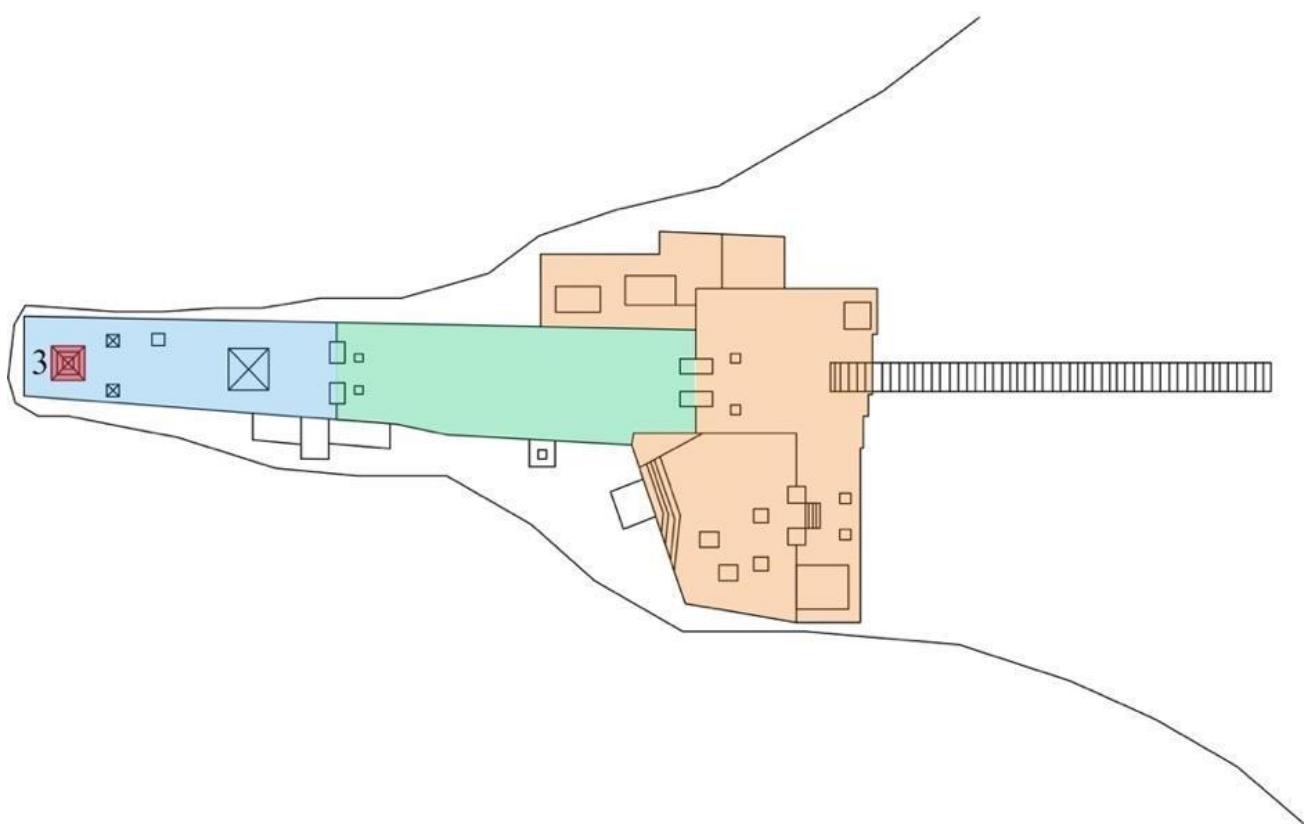

Figur 5. Denah Pura Uluwatu

(Sumber: Tim Hibah Dikti 2016) 


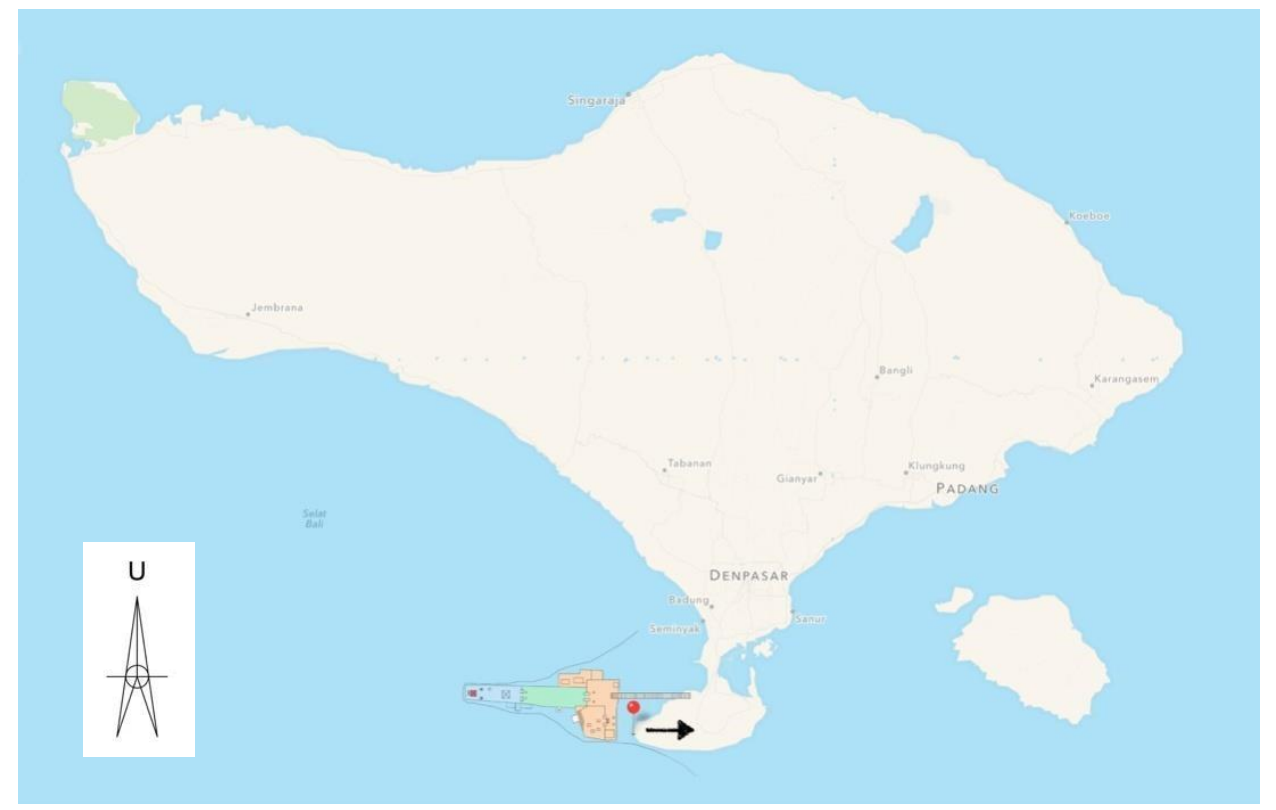

Figur 6. Orientasi Meru pada Pura Uluwatu

(Sumber: Tim Hibah Dikti 2016)

\subsection{PROPORSI}

Analisis proporsi ditinjau dari pengukuran perbandingan bangunan Meru dari dokumentasi foto. Angka-angka yang digunakan antara lain tinggi total bangunan meru (HT), tinggi kepala meru (Hr), tinggi badan meru (Hbd), tinggi kaki meru (Hbs), lebar atap paling atas (Wrt), lebar atap paling bawah (Wrb), lebar badan meru (Wbd), dan lebar kaki meru (Wbs). Ukuran perbandingan tersebut menggunakan aplikasi AutoCAD dengan memasukan foto hasil observasi lalu menggunakan tool dimension aligned (dimaligned).

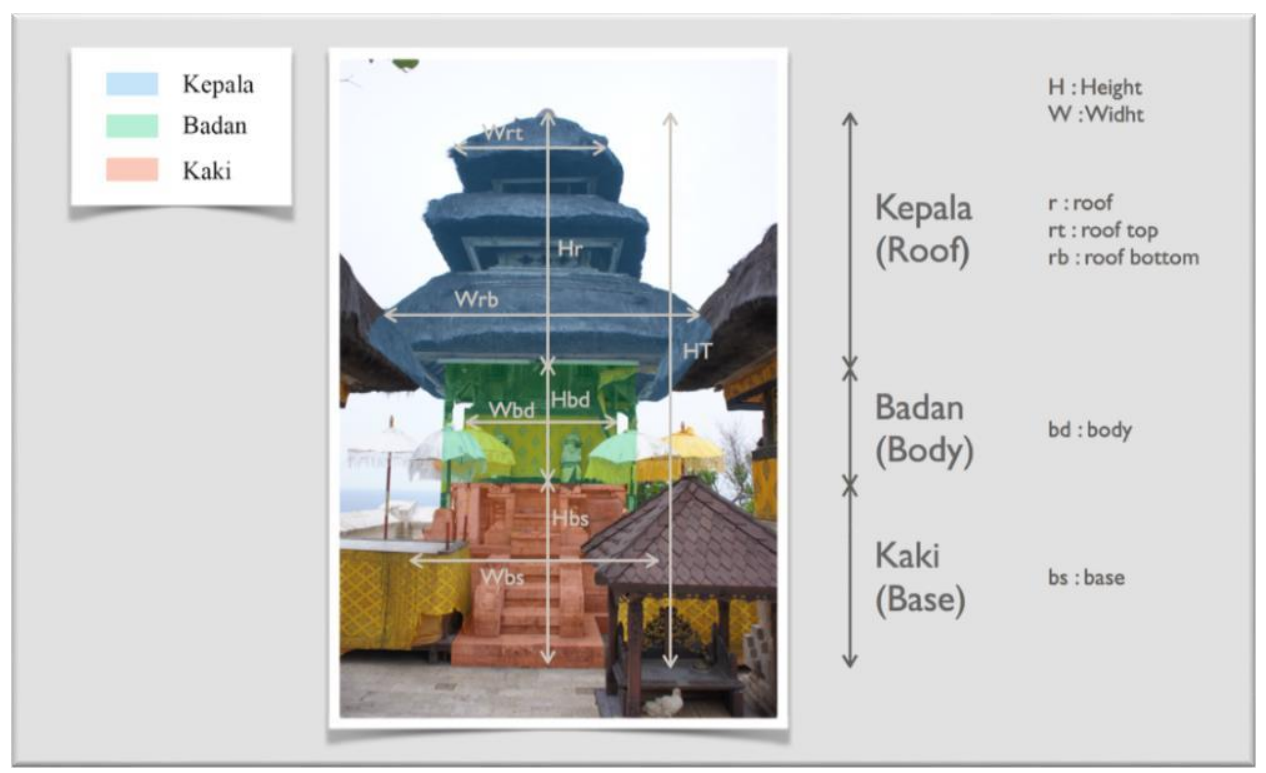

Figur 7. Patokan Proporsi Bangunan Meru

(Sumber: Tim Hibah Dikti 2016) 
Dalam penggunaan cara seperti ini, terdapat banyak faktor yang dapat membuat angka yang didapat tidak valid, seperti jarak pengambilan foto, arah kemiringan pengambilan foto, dll. Oleh karena itu, angka yang didapat dari AutoCAD tersebut dianggap sebagai konstanta perbandingan, dimana semua angka dibagi dengan Wrt, sehingga Wrt $=1.00$.

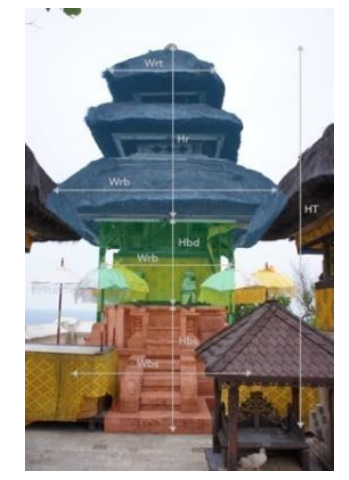

Figur 8. Meru (3) Pura Uluwatu

\begin{tabular}{|c|c|}
\hline $\mathbf{H}$ & 2.85 \\
\hline $\mathbf{H r}$ & 1.50 \\
\hline $\mathbf{H b d}$ & 0.71 \\
\hline $\mathbf{H b s}$ & 0.65 \\
\hline Wrt & 1.00 \\
\hline Wrb & 2.00 \\
\hline Hbd & 1.15 \\
\hline Wbs & 1.53 \\
\hline
\end{tabular}

Figur 9. Proporsi Meru (3) Pura Uluwatu

(Sumber: Tim Hibah Dikti 2016)

Dengan demikian, angka yang dianalisis merupakan angka perbandingan dalam meru itu sendiri. Lalu setelahnya angka-angka tersebut dibandingan dengan meru-meru lainnya yang memiliki jumlah tumpang atap yang sama. Wrt digunakan sebagai patokan pembagian dikarenakan pada kebanyakan kasus, angka pada Wrt merupakan angka terkecil.

Setelah mendapatkan angka-angka konstanta perbandingan, angka-angka tersebut dibandingkan dengan satu sama lain, contohnya HT dibandingkan dengan Hr, Hbd, Hbs, Wrt, Wrb, Hbd, dan Wbs. Setelah itu Hr dibandingkan dengan HT, Hbd, Hbs, Wrt, Wrb, Hbd, dan Wbs. Dan begitu pula seterusnya.

Angka yang didapat lalu dibandingan dengan meru-meru lain dengan jumlah tumpang yang sama, angka-angka yang hasil perbandingannya mendekati dinilai dapat menjadi patokan dalam proporsi bangunan Meru.

\subsection{SIMBOLISASI}

Berdasarkan informasi dari nasarumber Pak Nyoman Gelebet, diketahui bahwa bangunan Meru dapat dilihat peruntukannya kepada siapa melalui ukirannya: (a) Ukiran Dewi, berarti Meru diperuntukan petani (Dewi Sri - Air) (b) Ukiran Dewa, berarti Meru diperuntukan Dewa-Dewa (c) Ukiran Binatang, berarti Meru diperuntukan leluhur. (Dengan syarat tidak ada mata menonjol, atau gigi taring) (d) Ukiran Tokoh Wayang, berarti Meru diperuntukan leluhur.

Berdasarkan informasi dari narasumber di Pura Ulun Danu Batur, diketahui Dewa yang dilambangkan pada suatu bangunan Meru dapat dilihat dari jumlah tumpang atapnya: (a) Tumpang 3, 5, dan 7 melambangkan Dewa Wisnu (b) Tumpang 9 melambangkan Dewa Brahma (c) Tumpang 11 melambangkan Dewa Siwa. 


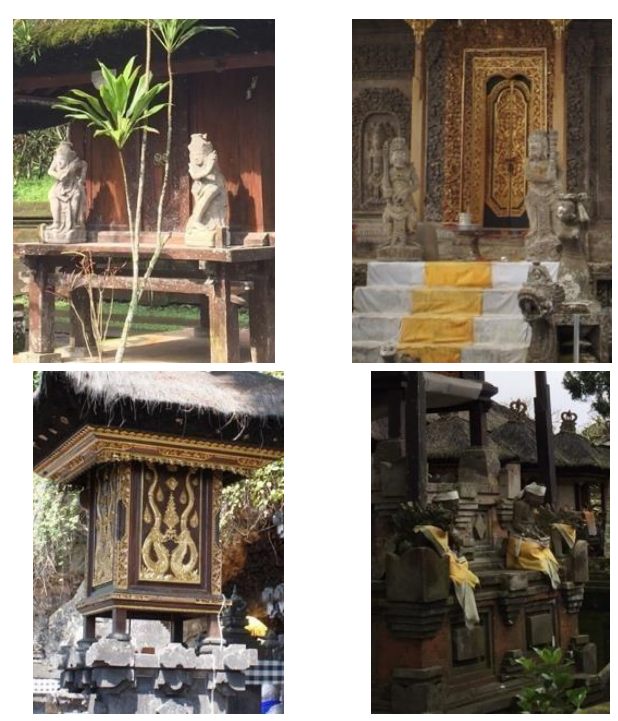

Figur 10. Ukiran Dewi, Dewa, Binatang, dan Wayang (Sumber: Tim Hibah Dikti 2016)

\section{KESIMPULAN}

\subsection{TATA LETAK}

Berdasarkan Tabel 4.13, hasil analisis pada Pura-Pura objek penelitian, terdapat beberapa persamaan dan perbedaan satu sama lain. Persamaan yang sangat jelas terlihat berupa letak bangunan Meru selalu di bagian Utama Mandala suatu Pura, yaitu bagian yang paling sakral.

Namun terdapat anomali pada Pura Ulun Danu Batur dimana salah satu bangunan Meru terdapat pada bagian Madya Mandala, yaitu bagian tengah. Perbedaan pada Pura Ulun Danu Batur ini menurut narasumber yang sudah menetap di daerah sana berpuluh-puluh tahun mengatakan bahwa pembangunan Meru di bagian Madya Mandala dikarenakan lahan pada Utama Mandala sudah tidak cukup lagi, sehingga terpaksa dibangun di Madya Mandala.



Figur 11. Kesimpulan Tata Letak

(Sumber: Tim Hibah Dikti 2016)

Orientasi bangunan Meru juga memiliki kesamaan yang cukup jelas. Bangunan Meru mayoritas terletak pada bagian Utara atau Timur pada Pura. Bangunan Meru yang terletak di Timur 
pada umumnya menghadap ke arah Barat. Sedangkan bangunan Meru yang terletak di Utara pada umumnya menghadap ke arah Selatan. Namun beberapa Meru di dalam Pura Penataran Agung Besakih memiliki orientasi ke 4 arah, dimana semua tampak bangunan Meru terdapat pintu.


Figur 12. Kesimpulan Tata Letak

(Sumber: Tim Hibah Dikti 2016)

Anomali pada orientasi terdapat di Pura Batukaru dan Pura Penataran Agung Besakih. Pada Pura Batukaru, terdapat 3 bangunan Meru yang terletak di bagian Barat Pura dan menghadap ke Timur. Pada Pura Penataran Agung Besakih terdapat beberapa bangunan Meru yang terletak di Barat. Orientasi pada seluruh Meru di Pura Penataran Agung Besakih juga berbeda seluruhnya dari Pura-pura yang lain. Diduga hal ini dikarenakan bentuk tapak yang miring sehingga orientasi Meru mengikuti bentuk tapak.

Orientasi Meru bila ditinjau lebih jauh lagi, terkait keberadaannya di Pulau Bali, masih belum ditemukan keseragaman yang valid / yang dapat dijadikan patokan. Alasan pemilihan orientasi bangunan Meru terhadap pulau Bali belum dapat diidentifikasikan, tetapi diduga karena alasan bentuk tapak yang mendukung arah Meru seperti demikian.

\subsection{PROPORSI}

Berdasarkan tabel 4.63, dapat ditarik kesimpulan bahwa terdapat beberapa perbandingan proporsi antar variabel bebas yang mirip antara satu sama lain. Angka-angka yang mendekati ini dipaparkan pada tabel 4.63 dengan warna kuning. Sedangkan warna hijau adalah nama variabel perbandingan yang memiliki kemiripan di setiap jumlah tumpang bangunan Meru. 


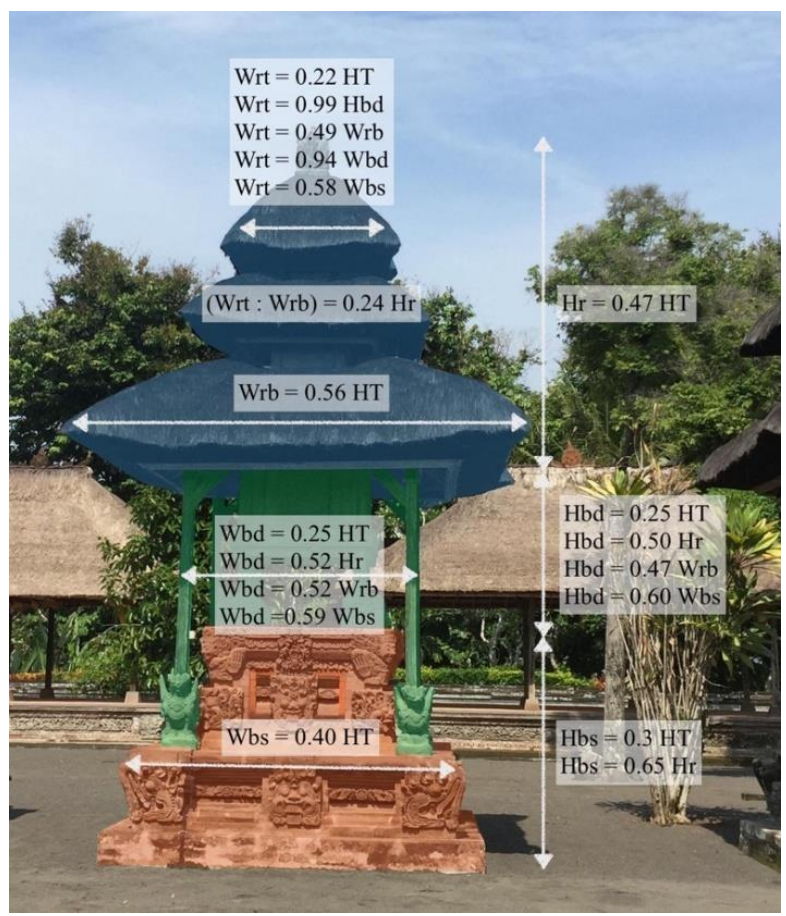

Figur 13. Kesimpulan Proporsi Meru Tumpang 3 (Sumber: Tim Hibah Dikti 2016)

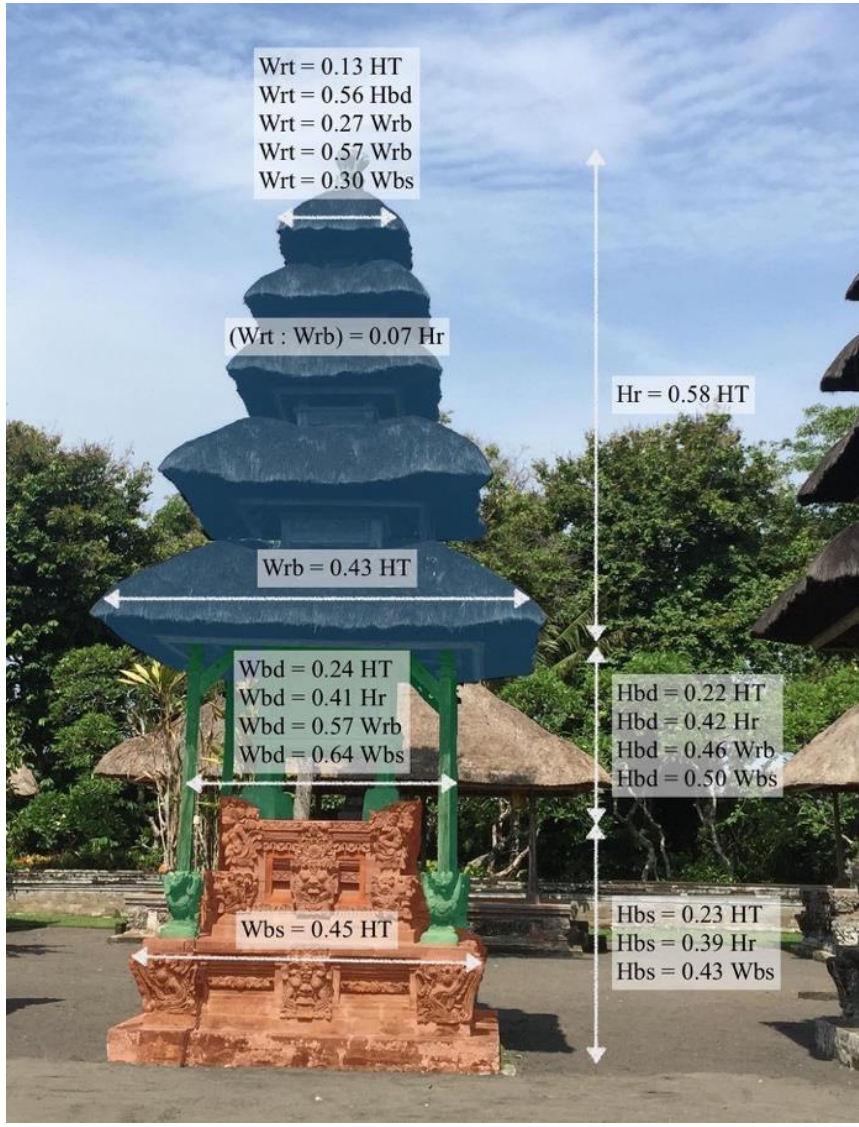

Figur 14. Kesimpulan Proporsi Meru Tumpang 7

(Sumber: Tim Hibah Dikti 2016) 


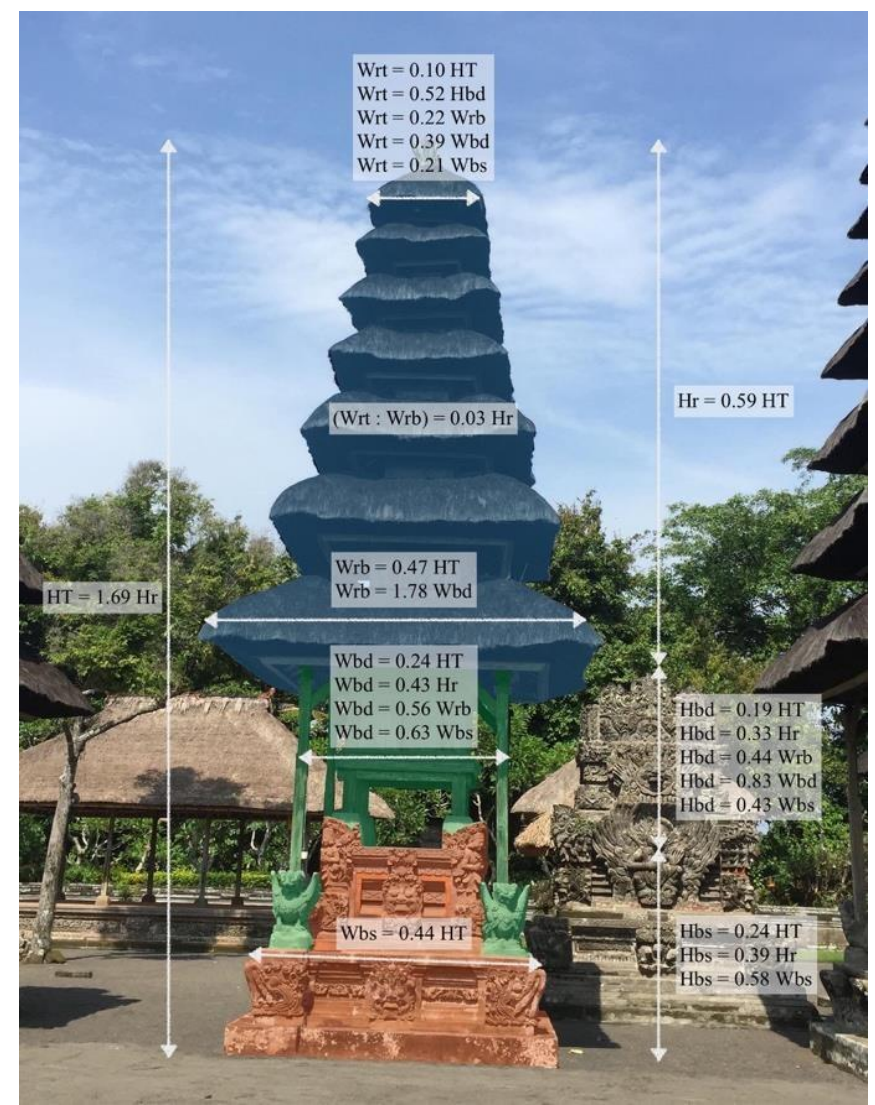

Figur 15. Kesimpulan Proporsi Meru Tumpang 5

(Sumber: Tim Hibah Dikti 2016) 


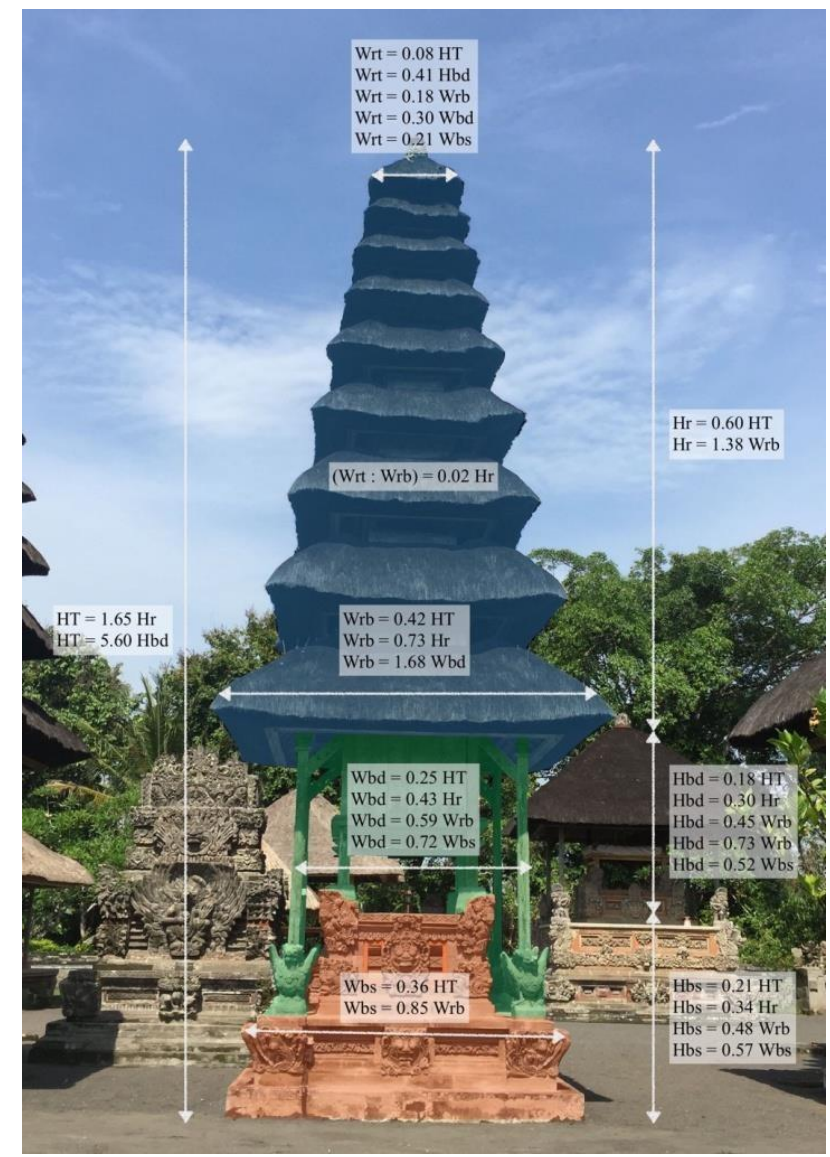

Figur 16. Kesimpulan Proporsi Meru Tumpang 9

(Sumber: Tim Hibah Dikti 2016) 




Figur 17. Kesimpulan Proporsi Meru Tumpang 11

(Sumber: Tim Hibah Dikti 2016)

\subsection{SIMBOLISASI}

Berdasarkan Tabel 4.64, dapat dilihat bahwa ternyata tidak ada pola yang dapat dijadikan standar atau patokan dalam simbolisasi suatu Meru. Dilihat dari hirarki, ukiran, maupun Stana, tidak terlihat repetisi yang dapat dijadikan patokan. Dalam Meru tumpang 3, 5, 7, 9, maupun 11 juga tidak selalu pasti bahwa di-Stana-kan oleh Dewa yang satu atau yang lainnya.

Kepastian yang sudah sangat jelas terkait simbolisasi pada bangunan Meru adalah suatu Meru pasti melambangkan sesuatu, dapat berupa Dewa, leluhur, atau yang lainnya. Patokan / standar dalam simbolisasi pada suatu Meru dimungkinkan dapat ditinjau dari aspek lain agar dapat dicari apa patokan dalam simbolisasi pada bangunan Meru.

\section{DAFTAR PUSTAKA}

Gelebet, I Nyoman. (1981). Arsitektur Tradisional Daerah Bali, Bali: Departemen pendidikan dan kebudayaan Proyek Inventarisasi dan Dokumentasi Kebudayaan Daerah.

Gelebet, I Nyoman. (1978). Arsitektur Tradisional Bali. Bali

Prajudi, Rahadian, H. (2001). Meru, Naskah Jurnal Tatanan Maret 2001.

Wiryatmika, Rai, I Made. (1988). Studi Komprehensip - Meru, Penelitian Bangunan Suci Tradisional Bali

Tujuan Filosofis dan Fungsi Meru (2000). Diakses pada 10 Februari 2016, dari 
http://www.babadbali.com/canangsari/hkt-meru-fungsi.htm

Meru (2014). Diakses pada 15 Februari 2016, dari http://bali-airport.com/detail/wisata/meru

Struktur dan Makna Pura di Bali Berdasarkan Asta Kosala-Kosali (2014). Diakses pada 1515 Februari 2016, dari http://www.komangputra.com/stuktur-makna-pura-di-bali-berdasarkanasta-kosalakosali.html 